\title{
Palladium(0)-Catalyzed Synthesis of Chiral Ene-allenes Using Alkenyl Trifluoroborates
}

\author{
Gary A. Molander, Erin M. Sommers, and Sharon R. Baker \\ Roy and Diana Vagelos Laboratories, Department of Chemistry, University of Pennsylvania, \\ Philadelphia, PA 19104-6323, USA
}

\begin{abstract}
Enantioenriched allenes serve as chiral transfer reagents, making them attractive synthetic targets. Herein the synthesis of enantioenriched allenes utilizing a $\operatorname{Pd}(0)$-catalyzed cross coupling reaction of propargylic carbonates and -phosphates with alkenyl trifluoroborates is reported. Di-, tri-, and tetrasubstituted allenes were synthesized in moderate to high optical yields. Several racemic allenes possessing various functional groups were also synthesized.
\end{abstract}

\section{Introduction}

Allenes are becoming increasingly important as synthetic targets, both in natural products and in other biologically active compounds. ${ }^{1}$ Moreover, chiral allenes with appropriate substitution are uniquely powerful intermediates for organic synthesis, translating axial chirality to central chirality. ${ }^{2}$ For these reasons, our laboratory seeks to develop methods for the efficient, stereoselective synthesis of enantiomerically enriched allenes. Previously the synthesis of chiral non-racemic allenes by cationic chromium(III) catalysis has been reported. ${ }^{3}$ However, this method possesses several drawbacks. Not only must substrates remain unfunctionalized, but a bulky tert-butyldimethylsilanoxy group serves as the leaving group, generating wasteful byproducts. In an effort to avoid these complications, a milder, more atom economical synthesis of enantioenriched allenes was desired.

Although a myriad of allene syntheses exist, ${ }^{4}$ few are achieved in high ee. ${ }^{5} S_{N} 2$ type reactions on optically active propargylic derivatives involving organocuprates are the most common and convenient methods for generating enantioenriched allenes..$^{5}$ Although chiral non-racemic propargylic alcohols are easily synthesized either by reduction of the conjugated alkyne${ }^{\text {ones }}{ }^{6}$ or from the asymmetric addition of alkynylmetallics to aldehydes, ${ }^{7}$ organocuprate methods suffer from some major drawbacks, including racemization of the product allenes under the reaction conditions. ${ }^{8}$ Attempts have been made to remedy this problem (e.g., utilizing mixed organocuprates, additives, and different leaving groups), but a general approach to the synthesis of optically active allenes remains elusive.

Easy access to enantioenriched substrates, mild reaction conditions, and atom economy make cross-coupling routes to form allenes extraordinarily attractive. ${ }^{9}$ Despite these favorable attributes, few general methods have been developed. Arylations using organozinc reagents have been reported with varying success. ${ }^{10}$ Depending on the substrate, anti selectivity ranges from 4:1 to complete stereoselectivity, and sterically unbiased internal and terminal propargylic substrates consistently yield allenes with less than $90 \%$ ee. The analogous Suzuki-Miyaura coupling reaction with boronic acids yielded an allene with complete transfer of chirality in 
the sole case reported. ${ }^{11}$ Likewise, one example has been reported where a 4-aryl-2,3-allenol was formed with complete retention of stereochemistry when a propargylic oxirane undergoes the cross coupling reaction with an aryl boronic acid. ${ }^{12}$ Although other aryl-, ${ }^{11}$ alkynyl-, ${ }^{13}$ alkenyl-, ${ }^{14}$ and alkylzinc ${ }^{10 \mathrm{a}}$ and -boron reagents have been used as coupling partners in racemic reactions, the scope of the reactions has not been extensively explored. Thus, the opportunity to refine this transformation exists. Because only one example of a cross-coupling type reaction with an alkenyl organoboron has been reported, ${ }^{14}$ alkenyl trifluoroborates as coupling partners served as a place to begin the studies described herein.

Potassium organotrifluoroborate salts have many attractive properties compared to other organoboron compounds. ${ }^{15}$ They are monomeric, air stable solids that generate non-toxic byproducts. This paper details the synthesis of allenes by $\operatorname{Pd}(0)$-catalyzed cross coupling of alkenyl trifluoroborates and propargylic carbonates. The functional group scope of the reaction is also presented. Additionally, the stereoselectivity of the reaction with propargylic phosphates is probed.

\section{Results and Discussion}

\section{Optimization of Reaction Conditions for Propargylic Carbonates and Exploration of Substrate Scope}

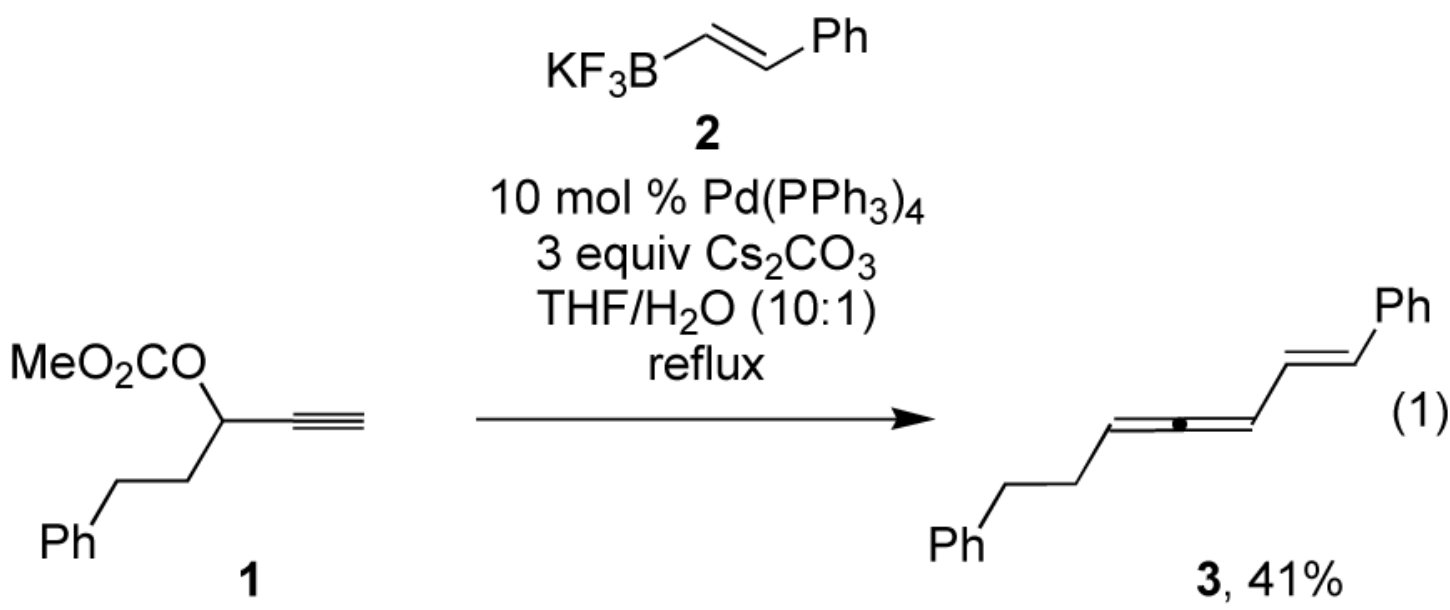

Initially, using $\mathrm{Pd}\left(\mathrm{PPh}_{3}\right)_{4}$ as a catalyst and $\mathrm{Cs}_{2} \mathrm{CO}_{3}$ as a base in $\mathrm{THF} / \mathrm{H}_{2} \mathrm{O}^{16}$ yielded $41 \%$ of the desired racemic ene-allene 3 from $\mathbf{1}$ (eq 1). Encouraged by this initial result, the reaction was optimized for palladium source, catalyst loading, base, solvent, and isolation conditions (Table 1). The yields given are quantitative GC yields using an internal standard and are based on complete consumption of the starting material. A comparison of different Pd catalysts proved that our original choice of $\mathrm{Pd}\left(\mathrm{PPh}_{3}\right)_{4}$ was indeed superior (Table 1, entry 3). The reaction does not proceed in the absence of a $\mathrm{Pd}(0)$ catalyst. After determining $\mathrm{Pd}\left(\mathrm{PPh}_{3}\right)_{4}$ to be the appropriate catalyst, several bases were screened. Entries 4-8 (Table 1) depict the results of changing the base. Inexpensive $\mathrm{NaHCO}_{3}$ proved to be the most efficient base. Using $\mathrm{NaHCO}_{3}$, the catalyst loading was lowered. Entries 9 and 10 (Table 1) display these results. A ten-fold decrease in catalyst loading from $10 \mathrm{~mol} \%$ to $1 \mathrm{~mol} \%$ created only a $10 \%$ decrease in yield (entries 6 and 9), although the reaction time was longer with less catalyst. However, lowering the catalyst loading to only $0.5 \mathrm{~mol} \%$ on this reaction scale not only lengthened the reaction time but also decreased the yield (entry 10). Therefore, 1 mol \% was chosen as the optimum catalyst loading on the reaction scale employed. It should be noted that up to $10 \mathrm{~mol}$ $\%$ was used in subsequent reactions to achieve the desired reaction efficiency and high yields. 
The final reaction parameter explored was the solvent. EtOH, DMSO, and THF without water were all tried. EtOH led to deprotection of 1 to yield only the free alcohol and no allene product. No reaction was observed in DMSO or THF without water. Despite the necessity of water, the water content could be lowered to $25: 1\left(\mathrm{THF} / \mathrm{H}_{2} \mathrm{O}\right)$ without observing any decrease in yield or reaction rate.

One more aspect of the reaction optimization bears mention. The palladium byproducts present appeared to polymerize/degrade the allene product. Very low isolated yields were obtained initially. To eliminate this problem, methods were investigated to remove the offending palladium from solution as quickly as possible upon completion of the reaction. Addition of adsorbent carbon black (Darco) followed by a period of stirring, exhibited a marked increase in isolated yield (e.g., $41 \%$ to $70 \%$ yield). It became standard practice to open the reactions to air and quench with Darco for all subsequent reactions. Except for the initial results (eq 1 and Table 1, entries 2 and 3), the yields reported herein reflect this work-up protocol.

After optimizing the reaction parameters, the functional group tolerance was explored. The results are presented in Table 2. Many functional groups were compatible with the reaction conditions. For example, nitrile, naked and protected alcohol, amine, chloride, and sulfurcontaining substrates tolerated the reaction conditions, producing racemic ene-allenes in moderate to good yields. Aldehyde $\mathbf{1 8}$ was the exception, producing only $19 \%$ of the allene. The basic conditions necessary for the reaction may have led to aldol products or polymerization, lowering the yield. The moderate yields of the remaining substrates can be explained by the above mentioned work-up protocol. The Darco necessary to achieve reasonable yields may also sequester the product. Excessive solvent washes of the Darco will release the problematic palladium. As discussed below, phosphates were thermally unstable, highlighted by the results in entries 3 and 11. Unlike their carbonate counterparts (entries 5 and 10, respectively), the phosphates suffered from lower yields. To synthesize an allene capped with a trimethylsilyl group, $\mathbf{3 1}$ was subjected to the reaction conditions. Instead of isolating the desired TMS-substituted allene, a small amount (17\%) of deprotected product was observed. The alkynyl-TMS might be readily deprotected under the basic reaction conditions, or the fluorine-containing trifluoroborate byproducts may have removed TMS from the alkyne or allene. More robust silyl protecting groups were not explored.

\section{Probing the Stereospecificity of the Reaction - Optimization and Application}

Based on previous literature reports of similar transformations, the substitution step was anticipated to proceed with inversion to generate allenyl-Pd I (Scheme 1) while the transmetalation/reductive elimination steps would occur with retention of configuration to yield an allene product III with overall anti substitution. ${ }^{2 \mathrm{~b}}$ Therefore, an enantioenriched substrate should lead to an enantioenriched allene product. Carbonate $(R)-\mathbf{1}$ was subjected to the optimized reaction conditions (eq 2 ). Disappointingly, the product was nearly racemic.

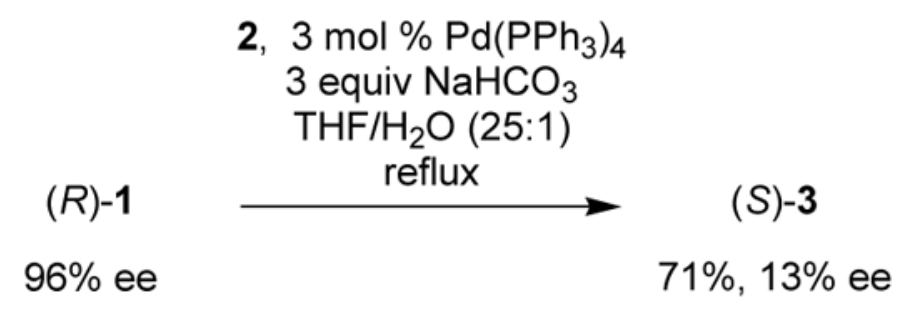

At this juncture, the literature was searched for examples of palladium-catalyzed racemization of allenes. To the best of our knowledge, palladium has been shown to racemize allenes by three mechanisms. In the first mechanism, allenes can be racemized through the $\eta^{1}$ - 
allenylpalladium(II) to $\eta^{1}$-propargylpalladium(II) interconversion (Scheme 2). ${ }^{17}$ When the Pd occupies the propargylic position, free rotation can occur, resulting in racemization. This mechanism proved beneficial for Mikami and coworkers in their report of a dynamic kinetic protonation of intermediate allenylmetals. ${ }^{17}$

By the second mechanism (Scheme 3), enantioenriched allenes are racemized by $\mathrm{Pd}(\mathrm{OAc})_{2^{-}}$ catalyzed bromopalladation/LiBr elimination. 18

In the third case, Ogoshi and coworkers postulated that an enantioenriched $\eta^{1}$-allenylpalladium (II) species will racemize over time due to the generation of a configurationally labile $\mu-\eta^{3}-$ allenyl/propargyldipalladium complex under normal catalytic conditions (Scheme 4).

Racemization was accelerated in the presence of oxygen and decreased when as little as 10 mol \% of $\mathrm{PPh}_{3}$ was added to the reaction. ${ }^{19}$

The reaction conditions were manipulated to maximize the enantioselectivity based on these three mechanisms. Unfortunately, success was limited. Palladium catalysts on solid supports were used to generate single-site catalysis and to circumvent the formation of potential bimetallic intermediates (Scheme 4). Reactions using $\mathrm{Pd}\left(\mathrm{PPh}_{3}\right)_{4}$ on polystyrene, FibreCat ${ }^{\mathrm{TM}}$ 1029, and FibreCat ${ }^{\mathrm{TM}} 1031$ exhibited a decreased reaction rate or no reaction, and any product isolated was racemic. Yoshida suggests that water assists formation of the bimetallic species (Scheme 4). ${ }^{12}$ To eliminate water, other alcoholic solvents, such as tert-amyl and sec-butyl alcohol were used. Unfortunately, these solvents completely inhibited the reaction. Water was introduced using hydrated bases: $\mathrm{KF} \cdot 2 \mathrm{H}_{2} \mathrm{O}$, CsOH$\cdot \mathrm{H}_{2} \mathrm{O}$, and $\mathrm{Na}_{2} \mathrm{CO}_{3} \cdot \mathrm{H}_{2} \mathrm{O}$ in THF led to the formation of racemic allenes. Mimicking Ogoshi's work, excess $\mathrm{PPh}_{3}$ was added to the reaction. Except for noticeably slowing the reaction, only a moderate rise in ee was observed when the substrate was fully consumed. Other metal catalysts $(\mathrm{Ni}, \mathrm{Rh}$, and $\mathrm{Cu}$ ) were employed with no success.

In a final bid to raise the ee, different leaving groups were examined. The acetate leaving group led to racemic product at a slower reaction rate than the propargylic carbonate. The slower reaction can be explained by the fact that the acetate anion acts as a ligand for palladium, retarding the rate-determining transmetalation step and thereby decreasing the reaction rate. 20 When an enantioenriched phosphate was subjected to the reaction conditions (eq 3), not only was there a rise in ee, but the reaction could be conducted at room temperature instead of at reflux. At this juncture, the catalyst/ligand combinations were screened again using a propargylic phosphate. An array of reactions using $\mathrm{PdCl}_{2}, \mathrm{Pd}(\mathrm{PhCN})_{2} \mathrm{Cl}_{2}, \mathrm{Pd}\left(\mathrm{MeCN}_{2} \mathrm{Cl}_{2}, \mathrm{Pd}\right.$ $(\mathrm{OAc})_{2}, \mathrm{Pd}_{2} \mathrm{dba}_{3}$, and $\left[\mathrm{Pd}\left(\text { allyl) } \mathrm{Cl}_{2} \text { as catalysts and } \mathrm{Ph}_{3} \mathrm{As} \text {, (2-furyl }\right)_{3} \mathrm{P}\right.$, dppe, dppb, and dppf as ligands were conducted. Each catalyst/ligand combination yielded products that were racemic. $\mathrm{Pd}\left(\mathrm{PPh}_{3}\right)_{4}$ remained the most viable catalyst for this transformation. Again different metals, bases, solvents, and additives were investigated to raise the ee; however, no additional headway was made. Under the countless reaction conditions tried, the ee of $\mathbf{3 4}$ was initially high, however $(S)$-33 failed to be fully consumed before racemization occurred.

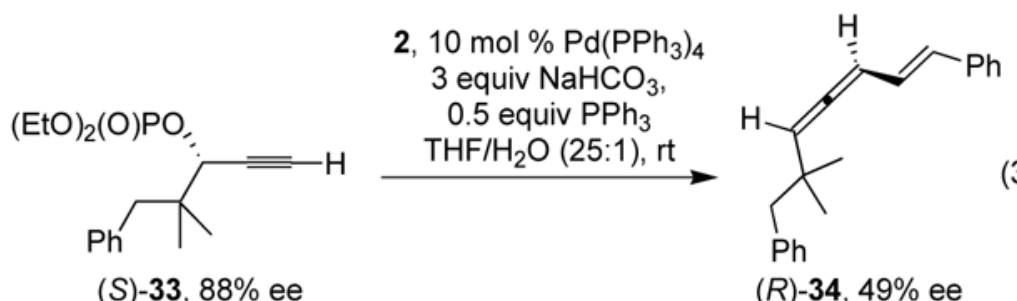

These empirical observations prompted an investigation into the nature of the racemization. We proposed that there was an initial rapid formation of allene possessing high ee followed 
by a prolonged period in which little to no additional product was formed and racemization of the product occurred. This idea was confirmed by examining the conversion versus the racemization of the product at several temperatures (Table 3 ).

As predicted, the ee decreased over time while the production of product tapered off. At room temperature the racemization was rapid, occurring within two minutes, while the reaction reached completion after $1 \mathrm{~h}$. Lowering the temperature was beneficial to both the conversion and ee, but a similar trend was observed. Because of a difficult analytical separation of the enantiomers of $\mathbf{3 4}$, another trifluoroborate was examined to corroborate the trend. Table 4 indicates the results of using vinyl trifluoroborate $\mathbf{7}$. Unlike the reaction with $\mathbf{2}$, the reaction was complete within $30 \mathrm{~s}$, but the same loss of ee was observed over time.

These results confirmed the hypothesis that the newly formed ene-allenes sequester the palladium, perhaps via initial coordination shown in Figure 1, and undergo racemization, effectively shutting down the desired coupling reaction. Alkenes with electron withdrawing substituents are better ligands for palladium based on back bonding into the empty $\pi^{*}$ orbital. 21 Because the phenyl group is more electronegative than a hydrogen substituent, ${ }^{22}$ allene 34 was a better ligand for $\operatorname{Pd}(0)$ than 35, explaining the slower turnover and more rapid racemization of $\mathbf{3 4}$. Additionally, the phenyl substituent may further coordinate to the metal center, increasing its affinity. Initially high ee's suggest that the first and third racemization mechanisms (Schemes 2 and 4) are not operating. If racemization occurred at the allenyl-Pd intermediate, any product formed would be racemic because racemization must necessarily occur before the transmetalation/reductive elimination step. Therefore, the $\mathrm{Pd}(\mathrm{II})$ racemization mechanism remains a possibility with $\mathrm{NaOP}(\mathrm{O})(\mathrm{OEt})_{2}$ or $\mathrm{NaHCO}_{3}$ playing the role of $\mathrm{LiBr}$; however, no experimental evidence for this proposal has been gathered. Furthermore, this mechanism seems unlikely due to the weakly nucleophilic character of the phosphate or bicarbonate anions compared to bromide in the reported example.

To expand the scope of the asymmetric reaction, several classes of alkenyl trifluoroborates were subjected to the reaction conditions. The results are displayed in Table 5 and reflect the optimized result for each trifluoroborate. (S)-33 reacted with vinyl trifluoroborate (7) to produce $(R)-35$ in $80 \%$ yield and $94 \%$ ee (Table 5 , entry 1 ). The less substituted trifluoroborates produced allenes possessing high ee (Table 5, entries 1 and 4). Conversely, the more substituted potassium 1-methyl-1-vinyl trifluoroborate (36) resulted in a poorer yield of $\mathbf{3 7}$, with a moderate loss of ee. Ironically, our test trifluoroborate $\mathbf{2}$ led to $\mathbf{5}$ in the poorest yield and ee (Table 5, entry 3). ${ }^{23}$ In the case of the 1,2-disubstituted trifluoroborate $\mathbf{3 8}$, the reaction time was extended to increase the conversion. This extra time negatively impacted the ee of the reaction (Table 5 , entry 4 ), but loss of ee was alleviated to some degree by decreasing the catalyst loading (Table 5, entry 5).

In addition to different classes of alkenyl trifluoroborates, substrates possessing different substitution patterns were subjected to the reaction conditions. Equations 4 and 5 illustrate the formation of

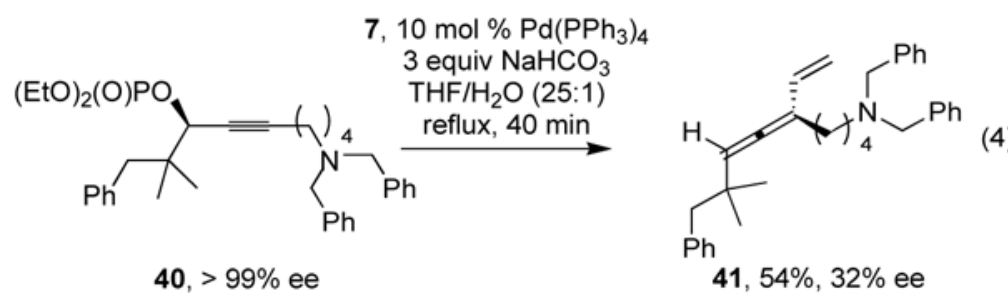

J Org Chem. Author manuscript; available in PMC 2008 August 9. 


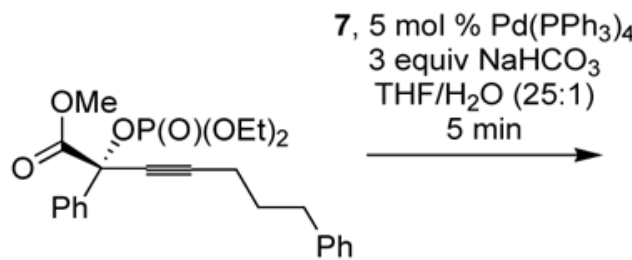

42, $74 \%$ ee

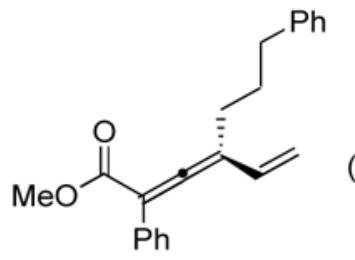

$4348 \%, 72 \%$ ee

enantioenriched tri- and tetrasubstituted allenes. In the case of $\mathbf{4 0}$, the reaction must be heated to reflux for reasonable conversion to $\mathbf{4 1}$. However, phosphates were thermally unstable at higher temperatures, resulting in a lower yield. Additionally, a high reaction temperature negatively impacted the ee. In contrast, the tetrasubstituted allene $\mathbf{4 3}$ was formed in moderate yield with high retention of ee. Although $\mathbf{4 2}$ was more sterically encumbered than $\mathbf{4 0}$, the phosphate was poised to be a much better leaving group because of its benzylic, propargylic, and tertiary character. Therefore, the reaction was performed at room temperature. Because the synthesis of chiral non-racemic tertiary propargylic alcohols has recently been reported, 24 this method is a convenient way to generate tetrasubstituted allenes in high ee.

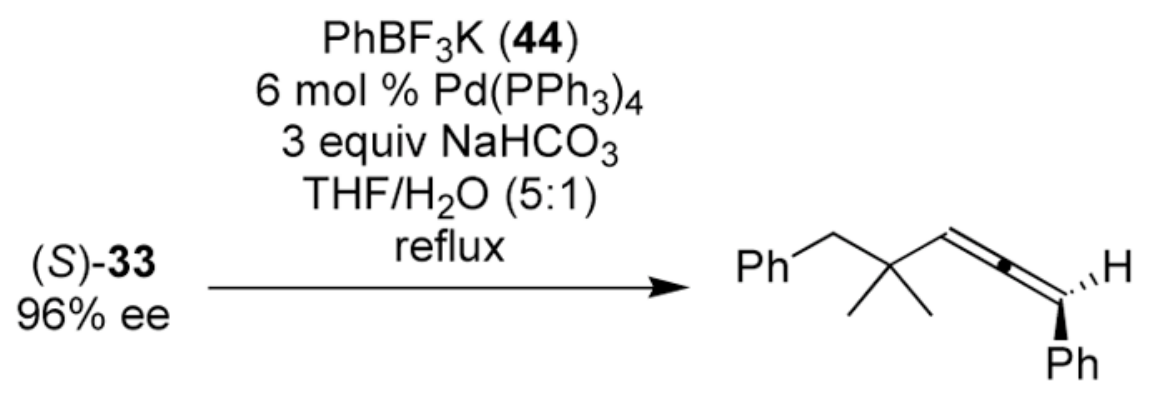

$45,26 \%, 80 \%$ ee

As a last area of interest, other classes of trifluoroborates, such as aryl, alkynyl, or alkyl were subjected to the reaction conditions optimized for alkenyl trifluoroborates. Unfortunately, only an aryl trifluoroborate coupled to generate an allene under these conditions (eq 6). Interestingly, aryl allenes appear to be more resistant to racemization. After forty minutes at reflux, $\mathbf{4 5}$ was isolated in $80 \%$ ee. This result correlates with Yoshida's successful coupling of an aryl boronic acid and a carbonate at $100{ }^{\circ} \mathrm{C} .{ }^{12}$ Alkynyl- and alkyl trifluoroborate coupling partners did not yield any coupled product upon work-up. In the case of the alkyl coupling, almost complete decomposition of the starting material was observed after two hours at reflux.

\section{Conclusions}

Ene-allenes were synthesized in low to high enantiomeric excess depending on the trifluoroborate coupling partner and product formed. To the best of our knowledge, this report marks the first time that ene-allenes have been synthesized asymmetrically. Based on experimental observation of stunted conversion and rampant loss of ee over time, we propose that racemization occurs after the allene is formed by an unknown mechanism. Rapid racemization of electron-poor ene-allene products (i.e., alkenes bearing a phenyl substituent) further supports this proposal because these compounds serve as better ligands for palladium than ene-allenes bearing hydrogen or methylene substituents. In addition to synthesizing enantioenriched di-, tri-, and tetrasubstituted allenes, functional group tolerance was exhaustively examined. Despite the poor yield of an aldehyde and the loss of a TMS protecting group, all other cases (nitrile, alcohol, silyl ether, amine, thioether, and sulfone) provided 
moderate to good yields of allenes. Although alkynyl- and alkyl trifluoroborates failed to couple under the reaction conditions, a chiral non-racemic aryl allene was synthesized in $83 \%$ optical yield. Furthermore, a reproducible work-up procedure to remove the rogue palladium was devised. The continued development of methods for the synthesis of enantioenriched allenes is ongoing in our laboratory.

\title{
Experimental Section. Cross-coupling Reaction to Form Enantioenriched Allenes, Method A
}

The alkenyl trifluoroborate, $\mathrm{Pd}\left(\mathrm{PPh}_{3}\right)_{4}$, and $\mathrm{NaHCO}_{3}$ were combined in a round bottom flask. The flask was evacuated and refilled with nitrogen, and THF $(3 \mathrm{~mL})$ and $\mathrm{H}_{2} \mathrm{O}(200 \mu \mathrm{L})$ were added. In a separate flask, the propargyl phosphate was degassed by evacuation or by the freeze/ pump/thaw method and refilled with nitrogen. The substrate was then dissolved in THF (1 $\mathrm{mL}$ ). The substrate solution was transferred via cannula into the catalyst solution. The flask containing the substrate was washed with THF $(1 \mathrm{~mL})$, which was also transferred to the reaction mixture. The reaction time was calculated beginning with the first drop of substrate transferred. At the completion of the reaction, Darco was added and the flask was left uncapped. After stirring for $30 \mathrm{~min}$ to $1 \mathrm{~h}$, the mixture was filtered through a short plug of Celite to remove the Darco. The plug was washed with $\mathrm{Et}_{2} \mathrm{O}$. The solution was transferred to a separatory funnel where the organic layer was washed three times with brine $(1 \mathrm{~mL}$ each time). The ethereal layer was dried with $\mathrm{MgSO}_{4}$, filtered, and concentrated. The crude product was then purified via column chromatography with appropriate conditions for each allene product (see Supporting Information).

\section{Cross-coupling Reaction to Form Racemic Allenes from Carbonates/Phosphates, Method B}

The alkenyl trifluoroborate, $\mathrm{Pd}\left(\mathrm{PPh}_{3}\right)_{4}$, and $\mathrm{NaHCO}_{3}$ were combined in a round bottom flask with a side arm. The flask was fitted with a reflux condenser and was evacuated and refilled with nitrogen, and THF $(3 \mathrm{~mL})$ and $\mathrm{H}_{2} \mathrm{O}(200 \mu \mathrm{L})$ were added. In a separate flask, the propargyl carbonate/phosphate was degassed by evacuation or by the freeze/pump/thaw method and refilled with nitrogen. The substrate was then dissolved in THF $(1 \mathrm{~mL})$. The substrate solution was transferred via cannula into the catalyst solution. The flask containing the substrate was washed with THF $(1 \mathrm{~mL})$, which was also transferred to the reaction mixture. The reaction was then heated to reflux. At the completion of the reaction, Darco was added and the flask was left uncapped. After stirring for $30 \mathrm{~min}$ to $1 \mathrm{~h}$, the mixture was filtered through a short plug of Celite to remove the Darco. The plug was washed with $\mathrm{Et}_{2} \mathrm{O}$. The solution was transferred to a separatory funnel where the organic layer was washed three times with brine $(1 \mathrm{~mL}$ each time). The ethereal layer was dried with $\mathrm{MgSO}_{4}$, filtered, and concentrated. The crude product was then purified via column chromatography with appropriate conditions for each allene product (see Supporting Information).

\section{Supplementary Material}

Refer to Web version on PubMed Central for supplementary material.

\begin{abstract}
Acknowledgements
We thank the National Institutes of Health (GM35249), Merck Research Laboratories, and Amgen for generous support
\end{abstract} of this work. We thank Johnson-Matthey for their generous contribution of catalysts.

\section{References}

1. Hoffman-Röder A, Krause M. Angew Chem, Int Ed Engl 2004;43:1196-1216. [PubMed: 14991780]

2. A few examples: (a) Marshall JA, Bourbeau MP. Org Lett 2002;4:3931-3934. [PubMed: 12599495] (b) Ma S, Wu S. Chem Commun 2001:441-442. (c) Marshall JA, Wolf MA. J Org Chem 1996;61:3238-3239. 
3. Molander GA, Sommers EM. Tetrahedron Lett 2005;46:2345-2349.

4. A representative sample. (a) Rona R, Crabbé P. J Am Chem Soc 1968;90:4733-4734. (b) Buchwald SL, Grubbs RH. J Am Chem Soc 1983;105:5490-5491. (c) Varghese JP, Knochel P, Marek I. Org Lett 2000;2:2849-2852. [PubMed: 10964381]

5. (a) Rona R, Crabbé P. J Am Chem Soc 1969;91:3289-3293. (b) Myers AG, Zheng B. J Am Chem Soc 1996;118:4492-4493. (c) Schultz-Fademrecht C, Wibbeling B, Fröhlich R, Hoppe D. Org Lett 2001;3:1221-1224. [PubMed: 11348199] (d) Shimizu M, Kurahashi R, Kitagawa H, Hiyama T. Org Lett 2003;5:225-227. 1221-1224. [PubMed: 12529146] (c) Shimizu M, Kurahashi T, Kitagawa H, Hiyama T. Org Lett 2003;5:225-227. [PubMed: 12529146]

6. (a) Nishizawa M, Yamada M, Noyori R. Tetrahedron Lett 1981;22:247-50. (b) Ramachandran PV, Teodorovic AV, Rangaishenvi MV, Brown HC. J Org Chem 1992;57:2379-2386. (c) Parker KA, Ledeboer MW. J Org Chem 1996;61:3214-3217. [PubMed: 11667191] (d) Matsumura K, Hashiguchi S, Ikariya T, Noyori R. J Am Chem Soc 1997;119:8738-8739.

7. (a) Boyall D, Frantz DE, Carreira EM. Org Lett 2002;4:2605-2606. [PubMed: 12123387] (b) El-Sayed E, Anand NK, Carreira EM. Org Lett 2001;3:3017-3020. [PubMed: 11554832] (c) Boyall D, López F, Sasaki H, Frantz DE, Carreira EM. Org Lett 2000;2:4233-4236. [PubMed: 11150207] (d) Frantz DE, Fässler R, Carreira EM. J Am Chem Soc 2000;122:1806-1807. (e) Frantz DE, Fässler R, Tomooka CS, Carreira EM. Acc Chem Res 2000;33:373-381. [PubMed: 10891055] (f) Maezaki N, Kojima N, Tominaga H, Yanai M, Tanaka T. Org Lett 2003;5:1411-1414. [PubMed: 12713286] (g) Pu L. Tetrahedron 2003;59:9873-9886.

8. Claesson A, Olsson L-I. J Chem Soc, Chem Commun 1979:524-525.

9. (a) Jeffery-Luong T, Linstrumelle G. Tetrahedron Lett 1980;21:5019-5020. (b) Ma S. Eur J Org Chem 2004:1175-1183. (c) Ogasawara M, Ikeda H, Nagano T, Hayashi T. Org Lett 2001;3:2615-2617. [PubMed: 11483074] (d) Lee K, Seomoon D, Lee P. Angew Chem, Int Ed Engl 2002;41:3901-3903. [PubMed: 12386886] (e) Ogasawara M, Ueyama K, Nagano T, Mizuhata Y, Hayashi T. Org Lett 2003;5:217-219. [PubMed: 12529144]

10. (a) Elsevier CJ, Stehouwer PM, Westmijze H, Vermeer P. J Org Chem 1983;48:1103-1105. (b) Dixneuf PH, Guyot T, Ness MD, Roberts SM. Chem Commun 1997:2083-2084. (c) Konno T, Tanikawa M, Ishihara T, Yamanaka H. Chem Lett 2000:1360-1361. (d) Elsevier CJ, Kleijn H, Boersma J, Vermeer P. Organometallics 1986;5:716-720. (e) Elsevier CJ, Mooiweer HH, Kleijn H, Vermeer P. Tetrahedron Lett 1984;25:5571-5572.

11. Yoshida M, Gotou T, Ihara M. Tetrahedron Lett 2004;45:5573-5575.

12. Yoshida M, Ueda H, Ihara M. Tetrahedron Lett 2005;46:6705-6708.

13. (a) Gueugnot S, Linstrumelle G. Tetrahedron Lett 1993;34:3853-3856. (b) Mandai T, Nakata T, Murayama H, Yamaoki H, Ogawa M, Kawada M, Tsuji J. Tetrahedron Lett 1990;31:7179-7180.

14. Moriya T, Miyaura N, Suzuki A. Synlett 1994:149-151.

15. Molander GA, Figueroa R. Aldrichimica Acta 2005;38:49-56.

16. Molander GA, Yun C-S, Ribagorda M, Biolatto B. J Org Chem 2003;68:5534-5539. [PubMed: 12839444]

17. Mikami K, Yoshida A. Angew Chem, Int Ed Engl 1997;36:858-860.

18. Horváth A, Bäckvall J. Chem Commun 2004:964-965.

19. Ogoshi S, Nishida T, Shinagawa T, Kurosawa H. J Am Chem Soc 2001;123:7164-7165. [PubMed: 11459499]

20. Hegedus, LS. Transition Metals in the Synthesis of Complex Organic Molecules. University Science Books; Sausalito, CA: 1999. p. 256

21. Spessard, GO.; Miessler, GL. Organometallic Chemistry. Prentice Hall; Upper Saddle River, NJ: 1997. p. 49

22. Carey, FA.; Sundberg, FA. Advanced Organic Chemistry, Part A: Structure and Mechanism. 4. Kluwer Academic/Plenum Publishers; New York, NY: 2000. p. 17

23. The apparent discrepancy between Table 2, entry 2 and Table 5, entry 3 can be attributed to the different isolation procedures. Table 2 results are based on GC and HPLC analysis of aliquots from the same reaction. Table 5 results were generated from isolated material.

24. Jiang B, Chen Z, Tang X. Org Lett 2002;4:3451-3453. [PubMed: 12323041] 


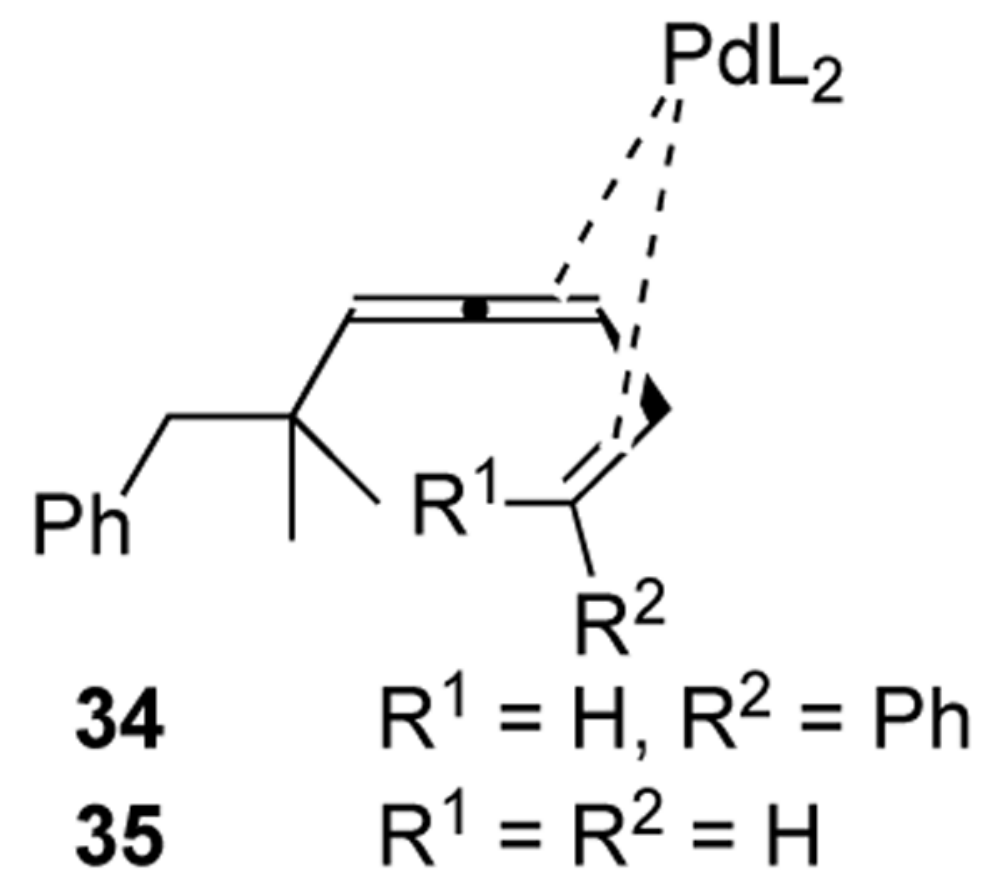

Figure 1.

Possible Coordination of $\operatorname{Pd}(0)$ with Ene-Allenes 34 and 35. 

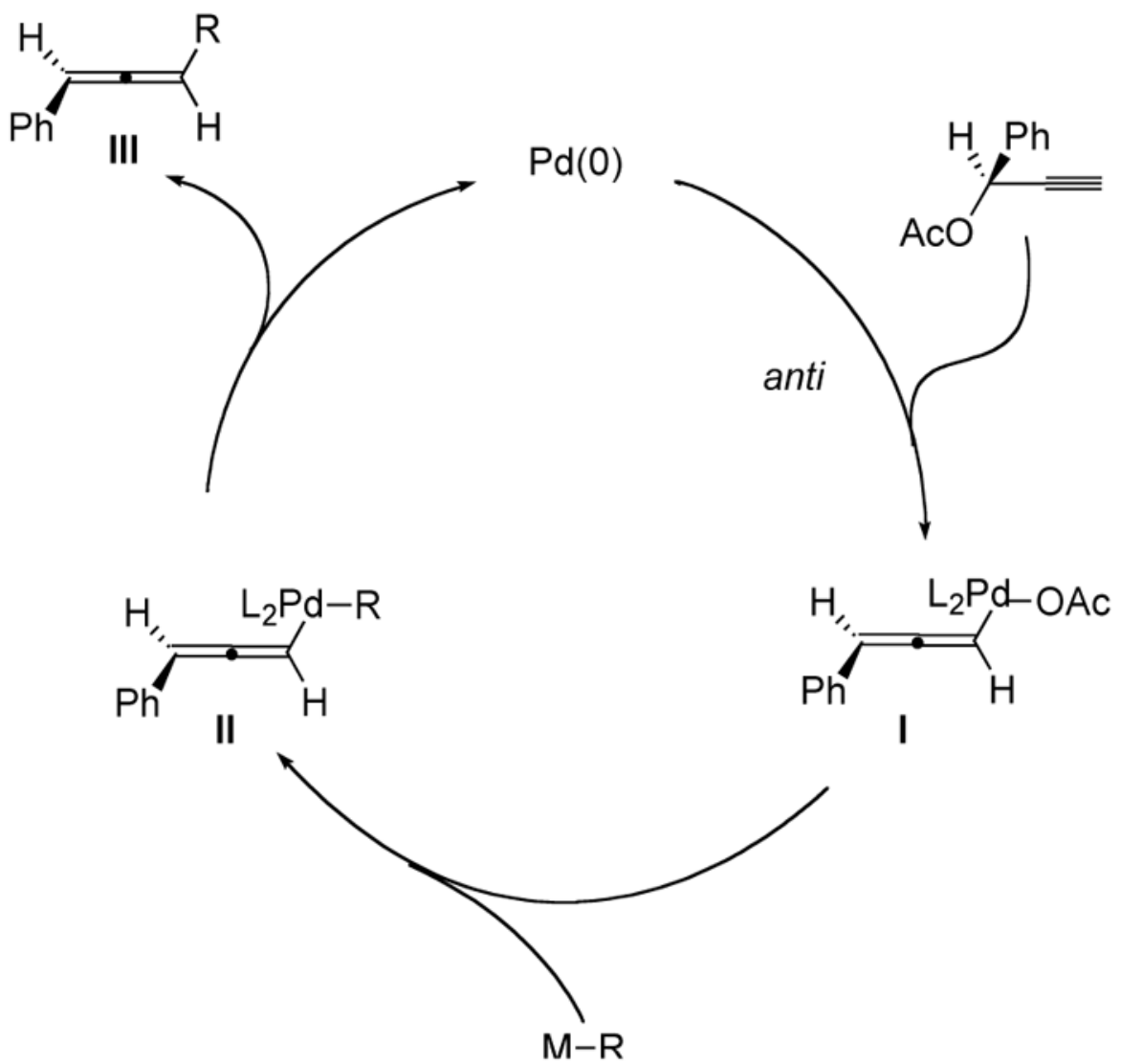

Scheme 1.

Mechanism of $\mathrm{Pd}(0)$-Catalyzed Cross Coupling Reaction to Form Allenes. 

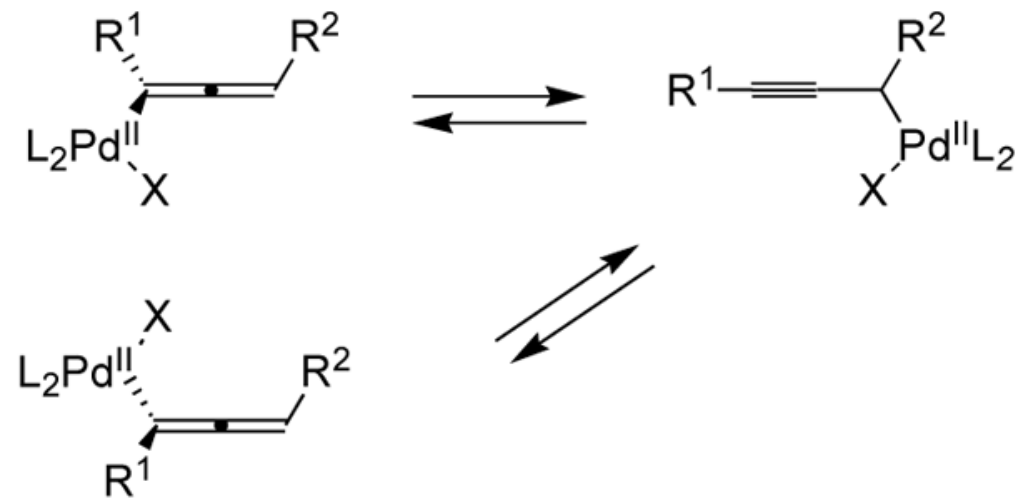

Scheme 2.

Possible Mechanism for Racemization of Allenes via Propargylic/Allenyl Pd Intermediate. 


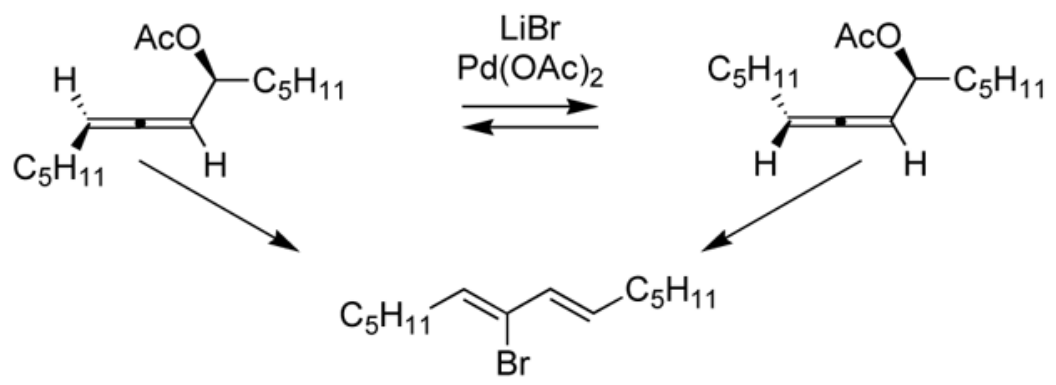

Scheme 3.

Racemization of Allenes with Pd(II) and LiBr via a Bromopalladation/Elimination Sequence. 


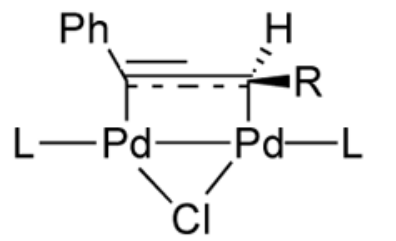

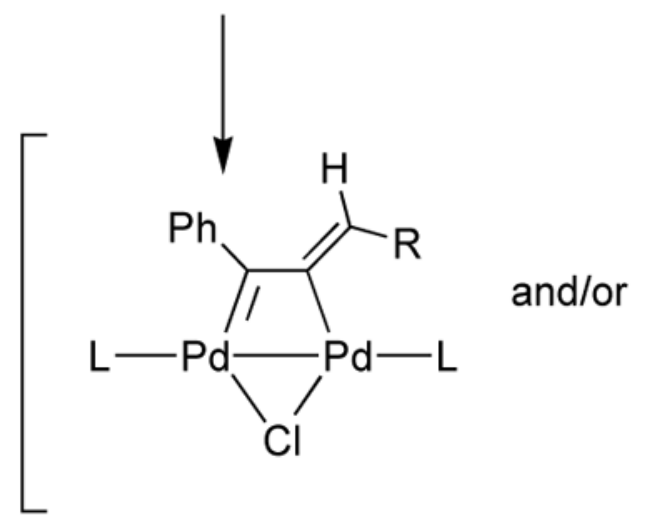

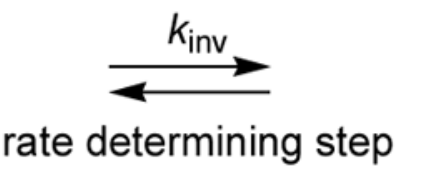
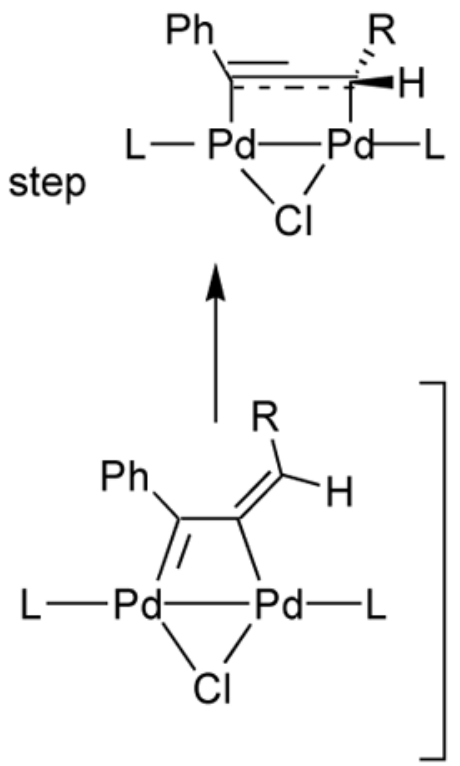

Scheme 4.

Racemization of Allenyl-Pd Intermediate via a Bimetallic Complex. 
Table 1

Optimization of Reaction Conditions

\begin{tabular}{|c|c|c|c|c|}
\hline entry & catalyst, ligand & base & time, $\mathrm{h}$ & $\%$ GC yield \\
\hline 1 & $\mathrm{PdCl}_{2}(\mathrm{dppf}) \cdot \mathrm{CH}_{2} \mathrm{Cl}_{2}(10 \mathrm{~mol} \%)$ & $\mathrm{Cs}_{2} \mathrm{CO}_{3}$ & 2 & starting material \\
\hline 2 & $\mathrm{Pd}(\mathrm{OAc})_{2}, 2 \mathrm{PPh}_{3}(10 \mathrm{~mol} \%)$ & $\mathrm{Cs}_{2} \mathrm{CO}_{3}$ & 2 & $14^{a}$ \\
\hline 3 & $\operatorname{Pd}\left(\mathrm{PPh}_{3}\right)_{4}(10 \mathrm{~mol} \%)$ & $\mathrm{Cs}_{2} \mathrm{CO}_{3}$ & 2 & $41^{a}$ \\
\hline 4 & $\mathrm{Pd}\left(\mathrm{PPh}_{3}\right)_{4}(10 \mathrm{~mol} \%)$ & $\mathrm{Cs}_{2} \mathrm{CO}_{3}$ & 2 & 93 \\
\hline 5 & $\mathrm{Pd}\left(\mathrm{PPh}_{3}\right)_{4}(10 \mathrm{~mol} \%)$ & $\mathrm{K}_{2} \mathrm{CO}_{3}$ & 7 & 66 \\
\hline 6 & $\mathrm{Pd}\left(\mathrm{PPh}_{3}\right)_{4}(10 \mathrm{~mol} \%)$ & $\mathrm{NaHCO}_{3}$ & 2 & 100 \\
\hline 7 & $\mathrm{Pd}\left(\mathrm{PPh}_{3}\right)_{4}(10 \mathrm{~mol} \%)$ & $i-\mathrm{Pr}_{2} \mathrm{NH}$ & 4 & 61 \\
\hline 8 & $\mathrm{Pd}\left(\mathrm{PPh}_{3}\right)_{4}(10 \mathrm{~mol} \%)$ & none & 24 & 0 \\
\hline 9 & $\operatorname{Pd}\left(\mathrm{PPh}_{3}\right)_{4}(1 \mathrm{~mol} \%)$ & $\mathrm{NaHCO}_{3}$ & 3 & 90 \\
\hline 10 & $\mathrm{Pd}\left(\mathrm{PPh}_{3}\right)_{4}(0.5 \mathrm{~mol} \%)$ & $\mathrm{NaHCO}_{3}$ & 4.5 & 58 \\
\hline
\end{tabular}

${ }^{a}$ Isolated yields. 
Table 3

Time vs. Conversion and \% ee Using 2.

\begin{tabular}{|c|c|c|c|c|}
\hline & $\begin{array}{l}-\mathbf{3 3} \\
\% \text { ee }\end{array}$ & $\begin{array}{l}\text { nol } \% \\
\text { quiv } \mathrm{N} \\
\mathrm{F} / \mathrm{H}_{2} \mathrm{C} \\
\mathrm{rt}\end{array}$ & 4 & \\
\hline entry & temp, ${ }^{\circ} \mathrm{C}$ & time, $\min$ & conversion, $\%^{a}$ & ee, $\%$ \\
\hline $\begin{array}{c}1 \\
2 \\
3 \\
4 \\
5 \\
6 \\
7 \\
8 \\
9 \\
10\end{array}$ & $\begin{array}{c}\mathrm{rt} \\
\mathrm{rt} \\
\mathrm{rt} \\
\mathrm{rt} \\
\mathrm{rt} \\
0 \\
0 \\
-15 \\
-15 \\
-40\end{array}$ & $\begin{array}{c}0.5 \\
2.5 \\
5 \\
12 \\
60 \\
5 \\
22 \\
5 \\
60 \\
15\end{array}$ & $\begin{array}{l}54 \\
73 \\
80 \\
88 \\
99 \\
80 \\
93 \\
92 \\
95 \\
90\end{array}$ & $\begin{array}{c}67 \\
0 \\
0 \\
0 \\
0 \\
85 \\
76 \\
80 \\
59 \\
74\end{array}$ \\
\hline
\end{tabular}

${ }^{a}$ Conversion based on quantitative GC analysis of starting material consumption. 
Table 4

Time vs. Conversion and \% ee Using 7.

\begin{tabular}{|c|c|c|c|}
\hline \multicolumn{4}{|c|}{$\begin{array}{c}\text { 7, } 1 \text { mol \% } \mathrm{Pd}\left(\mathrm{PPh}_{3}\right)_{4} \\
3 \text { equiv } \mathrm{NaHCO}_{3} \\
\mathrm{THF} / \mathrm{H}_{2} \mathrm{O}(25: 1) \\
\text { rt }\end{array}$} \\
\hline$\overline{\text { entry }}$ & time, $\min ^{a}$ & conversion, \% & ee, $\%$ \\
\hline $\begin{array}{l}1 \\
2 \\
3 \\
4 \\
5\end{array}$ & $\begin{array}{c}0.5 \\
1 \\
3 \\
4 \\
5\end{array}$ & $\begin{array}{l}>99 \\
>99 \\
>99 \\
>99 \\
>99\end{array}$ & $\begin{array}{l}98 \\
92 \\
78 \\
76 \\
50\end{array}$ \\
\hline
\end{tabular}

${ }^{a}$ Conversion based on quantitative GC analysis of starting material consumption 


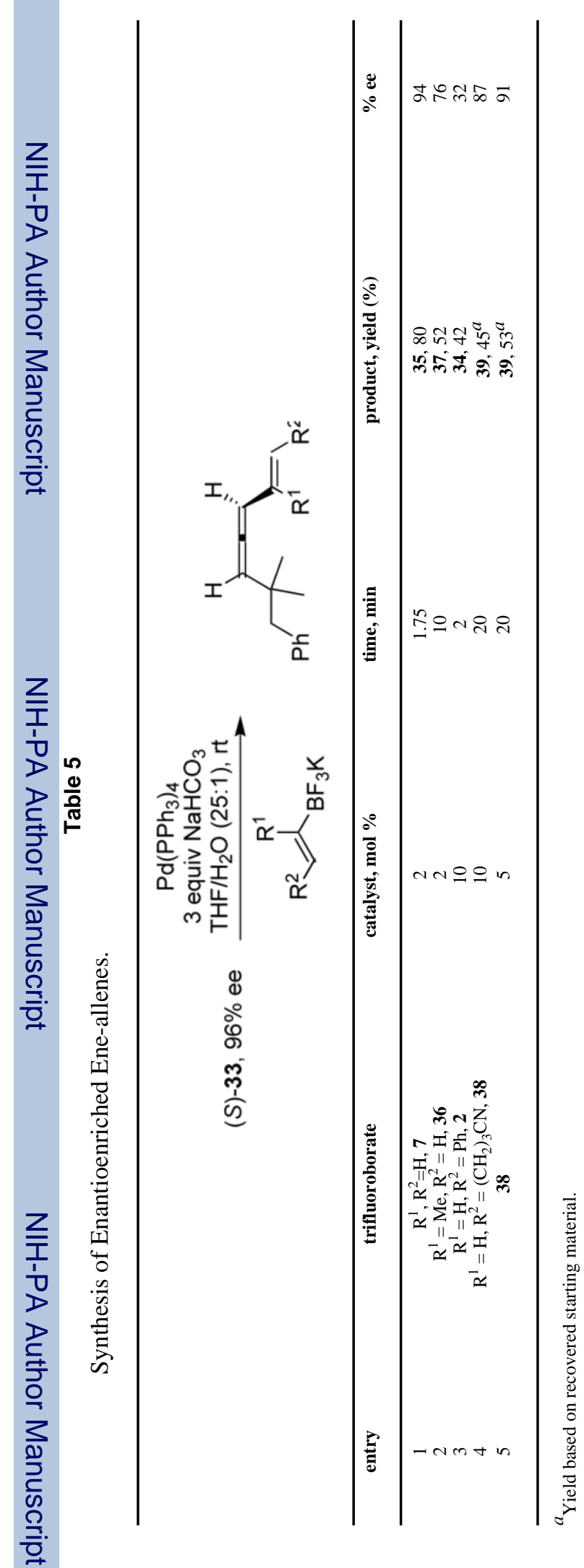

